\title{
WNT en Wwz bijten elkaar niet
}

\author{
Stapeling vergoedingen voor topfunctionaris mogelijk?
}

mr. Corine Vernooij en mr. Barbara Voermans*

\section{Inleiding}

Met de $\mathrm{WNT}^{1}$ is sinds 2013 de vrijheid van WNTplichtige instellingen en topfunctionarissen ingeperkt om individuele ontslagvergoedingen overeen te komen. Hiervoor is in de WNT een maximum geïntroduceerd van $€ 75.000$.

De $\mathrm{Wwz}^{2}$ heeft per 1 juli 2015 de transitievergoeding geintroduceerd. Iedere werknemer (dus ook de topfunctionaris) heeft - afhankelijk van de wijze waarop de arbeidsovereenkomst wordt beëindigd - op grond van de Wwz recht op een transitievergoeding indien de arbeidsovereenkomst minstens 24 maanden heeft geduurd.

Niet verrassend is de vraag of een wettelijk verschuldigde transitievergoeding mag cumuleren met een tussen een WNT-plichtige instelling en een topfunctionaris overeengekomen ontslagvergoeding, in het geval de som van de vergoedingen hoger uitvalt dan het WNT-maximum van $€ 75.000$. De Kantonrechter Amsterdam heeft zich recent over deze vraag gebogen. ${ }^{3}$ De kantonrechter stelt vast dat de transitievergoeding niet wordt genormeerd door de WNT. Dat betekent volgens de kantonrechter echter niet dat het een WNT-plichtige instelling en een topfunctionaris vrijstaat om naast de transitievergoeding nog een ontslagvergoeding overeen te komen, althans voor zover deze samen boven het WNT-maximum zouden uitkomen. De Kantonrechter Amsterdam steekt daarmee een stokje voor onbeperkte cumulatie van de transitievergoeding en een ontslagvergoeding.

Dat oordeel lijkt in het licht van de politieke en maatschappelijke discussie over excessieve ontslagvergoedingen in de (semi)publieke sector begrijpelijk. Een nadere analyse van de WNT, de Wwz en de wetsgeschiedenis leidt echter tot een andere conclusie, zo zal blijken uit dit artikel.

Hierna schetsen wij eerst de kaders van de WNT en de Wwz. Vervolgens geven we situaties aan waarin cumulatie van de transitievergoeding en een ontslagvergoeding

Corine Vernooij en Barbara Voermans zijn beiden advocaat bij Van Doorne N.V. De tekst van dit artikel is afgesloten op 31 oktober 2016.

1. Wet normering bezoldiging topfunctionarissen publieke en semipublieke sector.

2. Wet werk en zekerheid.

3. Ktr. Amsterdam 13 juni 2016, JAR 2016/176. zich kan voordoen. Daarna beantwoorden wij de vraag of onbeperkte cumulatie is toegestaan, waarbij bovengenoemde uitspraak aan bod komt. Wij sluiten af met de conclusie dat de transitievergoeding wel degelijk kan cumuleren met een ontslagvergoeding, ook als de transitievergoeding en de ontslagvergoeding gezamenlijk meer bedragen dan het WNT-maximum.

\section{Wettelijk kader}

\subsection{WNT}

De WNT verbiedt het met een topfunctionaris uitkeringen overeen te komen wegens beëindiging van het dienstverband (in dit artikel ook angeduid als 'ontslagvergoeding') die meer bedragen dan de bezoldiging (minus de onkostenvergoedingen) over de twaalf maanden voorafgaand aan de beëindiging van het dienstverband, met een bovengrens van $€ 75.000{ }^{4}$

Een hogere ontslagvergoeding is bij voorbaat nietig verklaard en de WNT-plichtige instelling is verplicht het te veel betaalde terug te vorderen. ${ }^{5}$ Besluit de WNT-plichtige instelling het bedrag niet terug te vorderen of weigert de topfunctionaris het bedrag terug te betalen, dan zal de minister die het anngaat het te veel betaalde (ook) kunnen terugvorderen bij de topfunctionaris. Het bedrag komt dan toe aan de staat (en niet aan de WNTplichtige instelling).

Het begrip 'uitkeringen wegens beëindiging van het dienstverband' is in de WNT gedefinieerd als de 'som van uitkeringen bij beëindiging van het dienstverband en beloningen betaalbaar op termijn die betrekking hebben op de beëindiging van het dienstverband, met uitzondering van uitkeringen die voortvloeien uit een algemeen verbindend verklaarde collectieve arbeidsovereenkomst of een wettelijk voorschrift'. ${ }^{6}$

Art. 2.10 lid 1 WNT: 'Partijen komen geen uitkeringen overeen wegens beëindiging van het dienstverband, die gezamenlijk meer bedragen dan de som van de beloning en de voorzieningen ten behoeve van beloningen betaalbaar op termijn over de twaalf maanden voorafgaand aan de beëindiging van het dienstverband, tot ten hoogste $€ 75000$. In geval van een dienstverband met een kleinere omvang dan het bij de verantwoordelijke gebruikelijk voltijdse dienstverband bedragen de uitkeringen ten hoogste $€ 75000$, vermenigvuldigd met het aantal uren waarop het dienstverband betrekking heeft en gedeeld door het aantal uren van een voltijds dienstverband.'

5. Art. 1.6 lid 2 WNT.

6. Art. 1.1 onderdeel i WNT. 
Ook de bezoldiging over de periode dat een topfunctionaris vooruitlopend op de beëindiging van het dienstverband geen taken meer vervult, kwalificeert als ontslagvergoeding. ${ }^{7}$ Vervult de topfunctionaris zijn taken niet meer als gevolg van vakantie, arbeidsongeschiktheid of een schorsing hangende een onderzoek, dan is geen sprake van een ontslagvergoeding maar van bezoldiging. ${ }^{8}$

De Uitvoeringsregeling WNT bevat een globale opsomming van componenten die in ieder geval kwalificeren als ontslagvergoeding. ${ }^{9}$ Een van de componenten betreft de door de rechter vastgestelde uitkeringen wegens beëindiging van het dienstverband. ${ }^{10}$ De betaling van een door de rechter vastgestelde uitkering die het WNT-maximum overschrijdt, is echter niet onverschuldigd. ${ }^{11}$ Ter illustratie: een door de rechter aan een topfunctionaris toegekende billijke vergoeding (op grond van artikel 7:673 lid $9 \mathrm{BW}$ of artikel 7:681 BW) kwalificeert als ontslagvergoeding, maar de betaling daarvan voor zover de billijke vergoeding het maximum van de WNT overschrijdt - is niet onverschuldigd. Hetzelfde geldt indien een bestuursrechter een hogere ontslagvergoeding dan het maximum toekent aan een topfunctionaris.

Ontslagvergoedingen die voortvloeien uit een algemeen verbindend verklaarde collectieve arbeidsovereenkomst ('avv-cao') of een wettelijk voorschrift (zowel Boek 7 Titel 10 BW als de uit de Ambtenarenwet afgeleide rechtspositieregelingen) vallen niet onder het begrip ontslagvergoeding en worden daardoor niet genormeerd door de WNT. Dergelijke vergoedingen zijn alleen uitgezonderd indien deze 'rechtstreeks, dwingend en eenduidig' uit de avv-cao's of wettelijke voorschriften voortvloeien. ${ }^{12}$ Aangezien weinig avv-cao's van toepassing zijn op topfunctionarissen, waren tot voor kort de ambtelijke rechtspositieregelingen de meest voorkomende uitzondering op de WNT-norm. ${ }^{13}$

De rechtvaardiging van deze uitzonderingen is gelegen in het feit dat WNT-plichtige instellingen en topfunctionarissen geen invloed kunnen uitoefenen op de hoogte van de vergoedingen. ${ }^{14}$ Het betreft collectieve regelingen waar een ministerieel besluit of een kabinetsbesluit

7. Art. 2.10 lid 3 WNT.

8. Art. 2 lid 2 onderdeel y Uitvoeringsbesluit WNT.

9. Art. 4 Uitvoeringsregeling WNT en toelichting op de Uitvoeringsregeling WNT.

10. In de toelichting op de Uitvoeringsregeling WNT, Stcrt. 2014, 36379 staat met betrekking tot dit onderdeel opgenomen: 'Betalingen die voortvloeien uit een rechterlijke uitspraak worden niet getoetst aan de maximumnorm. Als partijen de rechter gezamenlijk verzoeken om de arbeidsovereenkomst te ontbinden onder toekenning van een door hen vooraf afgesproken vergoeding, is er feitelijk geen sprake van een vergoeding die door de (kanton)rechter is vastgesteld; er vindt in de regel geen rechterlijke toets plaats. De ontbindingsbeschikking als zodanig is wel formeel van kracht, maar de afspraak tussen partijen kan strijdig zijn met de WNT als de afgesproken ontslagvergoeding uitstijgt boven het maximum.'

11. Art. 2.10 lid 1 WNT en art. 4 lid 1 onderdeel c Uitvoeringsregeling WNT.

12. Art. 4 lid 2 Uitvoeringsregeling WNT.

13. Kamerstukken // 2015/16, 34366, nr. 1, p. 22 van bijlage 'Eindrapport wetsevaluatie WNT 2013-2015'

14. Uitvoeringsregeling WNT, Stcrt. 2014, 36379 voor nodig is. Zodra individuele partijen invloed hebben op de hoogte van de vergoeding, gelden de uitzonderingen niet en is de ontslagvergoeding gemaximeerd. Een voorbeeld daarvan is de avv-cao die voorziet in een ontslagvergoeding naar billijkheid, in een concreet geval door de individuele partijen vast te stellen.

\subsection{Wwz}

Per 1 juli 2015 is de Wwz in werking getreden. Met de Wwz is de transitievergoeding geïntroduceerd. De transitievergoeding is een vergoeding waarop een werknemer (dus ook een topfunctionaris werkzaam op grond van een arbeidsovereenkomst) recht heeft op grond van de wet, mits aan een aantal in de wet neergelegde voorwaarden is voldaan. De meest voorkomende situaties in de $W_{w z}$ waarin een werknemer in aanmerking komt voor een transitievergoeding zijn, mits de arbeidsovereenkomst minstens 24 maanden heeft geduurd: de werkgever die de arbeidsovereenkomst met de werknemer opzegt (of dit nu met toestemming van het UWV is of met instemming van de werknemer), de op verzoek van werkgever ontbonden arbeidsovereenkomst en de arbeidsovereenkomst die van rechtswege eindigt en op initiatief van werkgever niet aansluitend is verlengd. Bij een beëindiging met wederzijds goedvinden is de transitievergoeding daarentegen niet verschuldigd.

De hoogte en de wijze waarop de transitievergoeding berekend moeten worden, zijn wettelijk vastgelegd. De transitievergoeding bedraagt maximaal $€ 77.000^{15}$ of een bedrag gelijk aan het loon over de laatste twaalf maanden als dat laatste bedrag hoger is dan $€ 77.000$.

\subsection{Wwz en WNT}

Voor de inwerkingtreding van de Wwz heeft de minister van Binnenlandse Zaken ('Minister') in het kader van de WNT een aantal keer stilgestaan bij de introductie van de transitievergoeding.

Zo is door de Minister in december 2014 aangegeven dat:

'vooralsnog niet voor gekozen [is] in deze regeling [lees: Uitvoeringsregeling WNT] gedetailleerde regels op te nemen over hetgeen tot de uitkeringen wegens beëindiging van het dienstverband in de zin van de WNT wordt begrepen. Gekozen is voor een globale opsomming van enkele vormen van ontslaguitkeringen (...). De belangrijkste reden dat afgezien is van een gedetailleerde regeling is dat met ingang van 1 juli 2015 de herziening van het ontslagrecht ingevolge de Wet werk en zekerheid in werking treedt en werknemers, waaronder ook topfunctionarissen, bij ontslag onder voorwaarden aanspraak kunnen maken op een transitievergoeding. Het is gewenst dat een gedetailleerde regeling van de ontslaguitkering op grond van de WNT, hierop afgestemd wordt.' 16 
Een jaar later, in december 2015, is de Minister nog explicieter ingegaan op de status van de transitievergoeding onder de WNT:

'(...) per 1 juli 2015 [is] de transitievergoeding op grond van de Wet werk en zekerheid (Wwz) ingevoerd en deze wordt ook niet door de WNT genormeerd. ${ }^{17}$

En over de verhouding tussen de transitievergoeding en de tussen een WNT-plichtige instelling en een topfunctionaris overeengekomen ontslagvergoeding heeft de Minister opgemerkt:

'Door de recente invoeringsdatum van de Wwz-transitievergoeding kon in het bestek van deze wetsevaluatie nog niet in beeld worden gebracht hoe de samenloop of cumulatie van deze transitievergoeding en de WNT-ontslagvergoeding in de praktijk uitwerkt. De komende periode zal de ontslagvergoedingspraktijk verder nauwgezet worden gevolgd. Het kabinet signaleert dat de samenloop - gelet op het karakter en oogmerk van beide regelingen - vraagt om een meer uniforme uitwerking.'

Verder is het volgens de Minister:

'(...) wenselijk voorstellen voor te bereiden om in een later stadium tot aanpassing te komen van het stelsel van normering van ontslagvergoeding op grond van de WNT om samenloop met de regeling van de transitievergoeding in het Burgerlijk Wetboek zoals deze per 1 juli 2015 van kracht is geworden, te reguleren.'

Die voorstellen zullen er op korte termijn niet komen, nu in de concept-memorie van toelichting op het voorontwerp van de Evaluatiewet WNT is opgemerkt dat het de verwachting is dat voor een zorgvuldige voorbereiding van de voorstellen meer tijd nodig is. ${ }^{18}$

Voornoemde uitlatingen staan niet op zich. Op de website van het ministerie van Binnenlandse Zaken, www. topinkomens.nl (onderdeel 'vraag en antwoord'), is het volgende opgenomen:

'Wordt een transitievergoeding als uitkering wegens beëindiging van het dienstverband beschouwd?

Uitkeringen die rechtstreeks, dwingend en eenduidig voortvloeien uit een algemeen verbindend verklaarde collectieve arbeidsovereenkomst (CAO) of een wettelijk voorschrift, vallen voor de toepassing van de WNT buiten de definitie van uitkeringen wegens beëindiging van het dienstverband en worden dus niet door de WNT genormeerd. Dat geldt dus ook voor de transitievergoeding indien en voor zover daar recht op bestaat ingevolge het BW. Een zogenoemde gelijkwaardige voorziening, als bedoeld in artikel $673 \mathrm{~b}$ van Boek $7 \mathrm{BW}$, is alleen uitgezonderd van nor-

17. Kamerstukken I/ 2015/16, 34366, nr. 1. p.4.

18. Concept-toelichting op het concept-wetsvoorstel Evaluatiewet WNT, p. 5 in te zien via www.internetconsultatie.nl/evaluatiewetwnt. mering van de WNT-ontslagvergoeding zoals neergelegd in artikel 2.10, eerste lid, en artikel 3.7, eerste lid, van de WNT, indien en voor zover deze is vastgelegd in een wettelijk voorschrift of algemeen verbindend verklaarde CAO.'

Kort samengevat: de Minister is van mening dat de transitievergoeding niet onder de reikwijdte van de WNT valt, dat cumulatie van de transitievergoeding en de ontslagvergoeding zich kan voordoen en dat het wenselijk is dat daarvoor een regeling komt. De Minister had voor de inwerkingtreding van de Wwz al zicht op het gegeven dat cumulatie van de transitievergoeding en de ontslagvergoeding zich zou kunnen voordoen en heeft welbewust hiervoor (nog) geen voorziening getroffen. Opvallend is dat de Minister het heeft over regulering van de samenloop en daarbij geen richting geeft hoe die samenloop zou moeten worden geregeld. Met andere woorden: de Minister geeft niet aan dat cumulatie van de transitievergoeding en de ontslagvergoeding in de toekomst niet mogelijk zal zijn.

\section{Situaties waarin cumulatie zich kan voordoen}

Wanneer doet cumulatie van de transitievergoeding en de ontslagvergoeding zich voor? In ieder geval niet bij een beëindiging met wederzijds goedvinden. In dat geval bestaat - als gezegd - geen wettelijke aanspraak op de transitievergoeding. Wel kan een maximale ontslagvergoeding van $€ 75.000$ worden overeengekomen.

Bij een andere wijze van beëindiging (ontbinding, opzegging of niet-voortzetting van de arbeidsovereenkomst voor bepaalde tijd) is de transitievergoeding mits aan alle voorwaarden is voldaan - wettelijk verschuldigd en is het de vraag of tevens ruimte bestaat voor een ontslagvergoeding.

Aanleiding om een ontslagvergoeding overeen te komen zou kunnen zijn dat een WN'T-plichtige instelling een hoger beroep in een ontbindingsprocedure wenst te voorkomen. Ook is de situatie denkbaar dat een vereniging - na het beëindigen van de statutaire positie van de topfunctionaris - de arbeidsovereenkomst opzegt en vervolgens afspraken wenst te maken met de betreffende topfunctionaris ter voorkoming van een procedure waarin de topfunctionaris een billijke vergoeding claimt. Afspraken daarover zouden kunnen worden neergelegd in een overeenkomst voor 'de losse eindjes'. Ook komt veelvuldig de situatie voor dat het niet wenselijk wordt geacht dat de topfunctionaris werkzaam zal blijven tot de datum dat de arbeidsovereenkomst eindigt. Aangezien de bezoldiging over een periode waarin de topfunctionaris vooruitlopend op de beëindiging van het dienstverband geen taken meer vervult als ontslagvergoeding kwalificeert, komt het regelmatig voor dat met (alleen) de vrijstelling al een ontslagvergoeding van $€ 75.000$ is gemoeid. 


\section{Beoordeling}

De vraag is of de transitievergoeding en de ontslagvergoeding mogen cumuleren als deze vergoedingen tezamen meer bedragen dan het WNT-maximum.

Daarvoor kijken we eerst naar de bewoordingen van de WNT en de Wwz. Nu de transitievergoeding een wettelijke aanspraak is en de hoogte alsook de wijze van berekenen uit de wet voortvloeit, volgt uit de WNT dat de transitievergoeding niet kwalificeert als ontslagvergoeding en de hoogte daarvan niet wordt genormeerd door de WNT ${ }^{19}$ De tekst van de WNT verzet zich verder ook niet tegen cumulatie van de transitievergoeding en de ontslagvergoeding. ${ }^{20}$ Ook de Kantonrechter Amsterdam erkent dat. ${ }^{21}$

Ook de Wwz verzet zich niet tegen cumulatie. Evenmin bestaat aanleiding de transitievergoeding op grond van de Wwz exclusief toe te kennen. ${ }^{22}$ Onder de $W_{w z}$ is het immers mogelijk een hogere vergoeding overeen te komen dan de wettelijk verschuldigde transitievergoeding. Dit komt in de praktijk veelvuldig voor (bijvoorbeeld in een sociaal plan).

Volgens de kantonrechter is het echter niet met de bedoeling van de WNT te verenigen dat een WNTplichtige instelling en een topfunctionaris naast de transitievergoeding een beëindigingsvergoeding van maximaal $€ 75.000$ mogen afspreken en dat de vergoedingen mogen cumuleren. De bedoeling van de WNT zou daarmee voor een groot deel teniet worden gedaan.

Het argument van de kantonrechter gaat wat ons betreft niet op. ${ }^{23}$ De wetgever beoogt met de normering van de ontslagvergoeding de vrijheid in te perken van WNTplichtige instellingen en topfunctionarissen om (bovenmatige) individuele ontslagvergoedingen af te spreken. De wetgever heeft daarbij uitdrukkelijk rekening gehouden met het bestaan van wettelijke vergoedingen en daarbij bepaald dat die niet gelden als ontslagvergoeding.

Niet goed valt in te zien waarom de vergoeding die voortvloeit uit een avv-cao of een rechtspositieregeling wel zou mogen samengaan met een ontslagvergoeding en een wettelijk verschuldigde transitievergoeding niet. ${ }^{24}$ De individuele topfunctionaris en de WNTplichtige instelling kunnen immers geen invloed uitoefenen op deze vergoedingen. Feit is dat bij opzegging of ontbinding door de WNT-plichtige instelling en het op

19. Hetgeen ook is bevestigd door de Minister, Kamerstukken II, $34366 \mathrm{nr}$ 1 , p. 4 en is eveneens vermeld op de website www.topinkomens.nl. Zie ook: Ktr. Midden-Nederland 17 juni 2016, ECLI:NL:RBMNE:2016:3347.

20. Zie ook: M. Benbrahim, 'Samenloop van vergoedingsregels in de Wwz, de WNT en de Wft', ArbeidsRecht 2016/6.

21. Ktr. Amsterdam 13 juni 2016, JAR 2016/176.

22. Zie ook $M$. Benbrahim, 'Samenloop van vergoedingsregels in de Wwz, de WNT en de Wft', ArbeidsRecht 2016/6.

23. Zie anders: annotatie van A.M. Helstone bij JAR 2016/176

24. Het voorgaande wordt nog onbegrijpelijker als vergoedingen die voortvloeien uit een sociaal plan of niet-avv-cao in de toekomst (ook) worden uitgezonderd van de WNT-normering, zie conceptwetsvoorstel Wijziging van de Wet normering bezoldiging topfunctionarissen publieke en semipublieke sector naar aanleiding van de eerste wetsevaluatie (Evaluatiewet WNT). initiatief van een WNT-plichtige instelling niet verlengen van een van rechtswege geëindigde arbeidsovereenkomst, de WNT-plichtige instelling op grond van de Wwz aan de topfunctionaris een transitievergoeding is verschuldigd. Dat bij een beëindiging met wederzijds goedvinden de transitievergoeding niet verschuldigd is, maakt bovenstaand gegeven niet anders.

Daar komt bij dat de Minister ruim voor inwerkingtreding van de $\mathrm{Wwz}$ wist en benoemde dat cumulatie mogelijk zou worden en ervoor heeft gekozen de WNT hier (nog) niet op aan te passen én dat op www. topinkomens.nl wordt aangegeven dat cumulatie mogelijk is. Daar doet niet aan af dat bij de parlementaire behandeling van de Wwz niet is ingegaan op de mogelijke cumulatie van de vergoedingen onder de WNT. Opmerkelijk genoeg worden de uitlatingen van de Minister en het ministerie van Binnenlandse Zaken in het geheel niet benoemd in de uitspraak.

Ook menen wij dat het niet redelijk is de transitievergoeding anders te behandelen dan andere wettelijke aanspraken. Ter vergelijking: het merendeel van de rechtspositieregelingen kent aanspraken tijdens een herplaatsingstermijn ${ }^{25}$ en werkloosheid toe die een (veel) grotere waarde dan $€ 75.000$ vertegenwoordigen. Zo heeft het CIBG geconcludeerd dat het een WNT-plichtige instelling was toegestaan een topfunctionaris die op grond van de toepasselijke rechtspositieregeling bij zijn ontslag naast WW aanspraak maakte op een anvullende uitkering, een aansluitende uitkering en vergoeding van het werkgeversdeel van de pensioenpremie, waarmee een bedrag van enkele tonnen was gemoeid, een ontslagvergoeding uit te keren tot een bedrag van $€ 75.000$. Slechts het meerdere was onverschuldigd betaald. ${ }^{26}$

Het karakter van de transitievergoeding maakt ook niet dat deze anders zou moeten worden behandeld dan de vergoedingen die voortvloeien uit een avv-cao of een wettelijk voorschrift. Laatstgenoemde vergoedingen compenseren ook de gevolgen van een beëindiging en houden rechtstreeks verband met de gevolgen van het ontslag.

Het moge duidelijk zijn dat onzes inziens cumulatie van de wettelijk verschuldigde transitievergoeding en de ontslagvergoeding mogelijk is, ook als de som van deze vergoedingen het maximum van de WNT overschrijdt.

Overigens zijn wij ons ervan bewust dat zich situaties kunnen voordoen waarin partijen zich in een schemergebied bevinden tussen bijvoorbeeld de opzegging met instemming en de beëindiging met wederzijds goedvinden. Denkbaar is dat een arbeidsovereenkomst wordt opgezegd met instemming van de topfunctionaris, terwijl partijen het feitelijk eens zijn over de voorwaarden van de beëindiging en zij deze overeenstemming niet (zoals gebruikelijker zou zijn) hebben vastgelegd in een vaststellingsovereenkomst, enkel om de transitievergoeding te kunnen laten cumuleren met de ontslagvergoe-

25. Zie in dit kader www.topinkomens.nl (onderdeel 'vraag en antwoord') waarin is opgenomen dat van-werk-naar-werktrajecten die rechtstreeks, dwingend en eenduidig uit een avv-cao of een wettelijk voorschrift voortvloeien niet kwalificeren als ontslagvergoeding.

26. www.hefpunt.nl/images/05_Onderzoek_naleving_WNT_1.pdf. 
ding. In die situatie dient wat ons betreft niet de vraag te worden beantwoord of de transitievergoeding en de ontslagvergoeding kunnen cumuleren, maar of de opzegging met instemming van kleur is verschoten naar een beëindiging met wederzijds goedvinden, in welk geval de topfunctionaris geen wettelijke aanspraak heeft op een transitievergoeding. ${ }^{27}$

Cumulatie van de transitievergoeding en de ontslagvergoeding is wat ons betreft niet alleen mogelijk, maar ook in een aantal gevallen wenselijk. De WNT merkt als gezegd de bezoldiging over een periode waarin de topfunctionaris vooruitlopend op de beëindiging van het dienstverband geen taken meer vervult aan als ontslagvergoeding. ${ }^{2829}$

Met de evaluatie van de WNT bleek dat de non-activiteitsbepaling in de praktijk als knellend en beperkend wordt ervaren. ${ }^{30}$ Die constatering kunnen wij beamen. In paragraaf 3 hiervoor schetsen we de veel voorkomende situatie waarin het door de WNT-plichtige instelling wenselijk wordt geacht dat de topfunctionaris al voor het einde van de arbeidsovereenkomst zijn werkzaamheden beëindigt. Gegeven de lange opzegtermijnen die doorgaans ten aanzien van topfunctionarissen gelden, zo wordt met bestuurders in de zorgsector veelal een opzegtermijn van zes maanden overeengekomen, komt het regelmatig voor dat met een vrijstelling van werkzaamheden een ontslagvergoeding van meer dan $€ 75.000$ is gemoeid. Het is in die gevallen voor topfunctionarissen weinig aantrekkelijk om in te stemmen met een vrijstelling, terwijl de WNT-plichtige instelling juist gebaat kan zijn bij een vrijstelling. Indien cumulatie niet mogelijk zou zijn, zou de WNT-plichtige instelling (vrijwel) geen vergoeding meer kunnen uitkeren aan een topfunctionaris anders dan de doorbetaling van de bezoldiging gedurende de opzegtermijn. Cumulatie kan in deze situatie een oplossing voor betrokkenen bieden.

\section{Conclusie}

De huidige tekst van de WNT staat cumulatie van de wettelijk verschuldigde transitievergoeding en een tussen een WNT-plichtige instelling en een topfunctionaris overeengekomen ontslagvergoeding toe, ook als de som van deze vergoedingen het maximum van de WNT overschrijdt. De Minister heeft aangegeven met een regeling voor deze cumulatie te zullen komen. Zolang hierin niet is voorzien, blijft cumulatie van de vergoedingen onzes inziens mogelijk.

Dit zou ook kunnen gelden voor de situatie waarin de kantonrechter wordt verzocht de arbeidsovereenkomst te ontbinden onder toekenning van een door partijen vooraf afgesproken vergoeding. Zie voetnoot 10.

28. Art. 2.10 lid 3 WNT

29. In lijn hiermee oordeelt de Kantonrechter Amsterdam dat de periode waarover de topfunctionaris is geschorst kwalificeert als ontslagvergoeding. De kantonrechter lijkt alleen bezwaren te hebben tegen uitbetaling van de ontslagvergoeding (en niet zozeer de vrijstelling die kwalificeert als ontslagvergoeding te willen beknotten).

30. Kamerstukken // 2015/16, 34366, nr. 1, p. 4.
De Kantonrechter Amsterdam besloot desalniettemin vooruit te lopen op de inwerkingtreding van een nadere regeling over cumulatie en bepaalt zelf of partijen naast een transitievergoeding een ontslagvergoeding mogen overeenkomen als de transitievergoeding het maximum van de WNT overschrijdt. Naar onze mening had het meer op de weg gelegen van de kantonrechter om te oordelen over de vraag of een transitievergoeding verschuldigd is. Uiteraard had de rechter daarbij kunnen overwegen dat cumulatie wat hem betreft uitgesloten zou moeten zijn, maar zijn oordeel had gegeven de huidige Wwz en WNT niet zo kunnen luiden. 